\title{
KELOMPOK NELAYAN DAN WANITA NELAYAN \\ DI SELAKAU DAN PEMANGKAT DALAM PENGOLAHAN UDANG REBON MENJADI BUBUK TERASI KERING
}

\author{
Nurliza \\ Agribisnis, Fakultas Pertanian, Universitas Tanjungpura \\ email : nurliza.spmm@gmail.com \\ Eva Dolorosa \\ Agribisnis, Fakultas Pertanian, Universitas Tanjungpura \\ email: edolorosa@gmail.com \\ Lucky Hartanti \\ Teknologi Hasil Pertanian, Fakultas Pertanian, Universitas Tanjungpura \\ Email : luckyhartantiabubakar@yahoo.co.id
}

\begin{abstract}
In Selakau and Pemangkat, Sambas district, has the largest shrimp carts, particularly as Togok season, February to May. Everyday, each group of fishermen caught the shrimp for $50 \mathrm{~kg}$ to 1 tons. However, they faced some obstacles. In the rainy season, the catch was quickly decompose due to the absence of cool storage so that the shrimp are processed into solid pasta and pack it in a piece of newspaper, leaves or ordinary plastic. As the result, the durability and the quality of products are limited and had poor quality. Thus, the stakeholders, especially the local government be worried about the miss an opportunity to get added value in shrimp processed into a solid paste which could be taken by stakeholders of other regions through the innovation of a package which made the products more attractive with specific brands. This IbM tried to improve the self-sufficient and capable of group of fisherman and their women in solid paste of shrimp processing into powder which had the longer durability to get more added value. IoM was designed with training and practice. The results shown that solid paste of shrimp was processed into powder; polypropylene plastic packaging was used to get safety, durable, and hygienic products; the product had a label with an attractive design; certificate of training; PIRT license; some tool aids, i.e. The cool storage, impulse sealer power pack, vacuum sealer, digital scales, drying oven, hand plastic sealer, sieving, the lighters, seals, labels, cutting board, apron, etc.
\end{abstract}

Keywords: drying, innovations, package, sieving, shrimp powder, the shrimp

\section{PENDAHULUAN}

Selakau dan Pemangkat merupakan salah satu kecamatan di Kabupaten Sambas memiliki andalan tangkapan uang rebon terutama pada musim togok, bulan Februari hingga Mei dimana setiap kelompok nelayan dapat mengumpulkan $50 \mathrm{~kg}-1$ ton/hari. Namun, kelompok nelayan menghadapi beberapa kendala, yaitu tangkapan cepat membusuk pada musim hujan akibat tidak 
tersedia cool storage. Oleh sebab itu, kelompok wanita nelayan berusaha mengolah udang rebon menjadi terasi berbentuk padat bulat atau segiempat dengan kemasan dari kertas koran, daun atau plastik biasa. Akibatnya, daya tahan, mutu, dan tampilanya rendah, sangat sederhana, dan kurang menarik. Hal ini sejalan dengan hasil kajian peneliti yang menunjukkan bahwa terasi udang rebon di Kabupaten Sambas memiliki karakteristik: (i) mutu/kualitas kurang terjaga/rendah; (ii) tersedia di pasar-pasar tradisional; (iv) tidak tahan lama; (v) keamanan produk rendah. Kendala tersebut telah menimbulkan kekhawatiran bagi stakeholders terutama pemerintah daerah setempat karena dapat memberikan peluang kepada pihak luar (pedagang di Kota Singkawang) untuk membeli terasi udang tersebut kemudian mengemasnya menjadi lebih menarik dengan merek tertentu sehingga pengolah tidak memperoleh nilai tambah tersebut.

Program IbM akan dirancang dengan pendekatan pelatihan dan praktek proses produksi serbuk terasi dan pengemasan terasi udang rebon untuk meningkatkan mutu, daya tahan, nilai tambah, dan daya saing produk. Hal ini selaras juga dengan hasil penelitian peneliti sebelumnya di kabupaten Sambas bahwa kemasan menjadi atribut preferensi konsumen dalam pengambilan keputusan pembelian produk olahan tradisional dibandingkan harga, bentuk, kandungan gizi, ketersediaan, dan jaminan. Program IbM ini diharapkan dapat mewujudkan mitra mandiri yang mempunyai kemampuan meningkatkan mutu dan daya tahan produk.

\section{METODE}

Pelaksanaan IbM dilaksanakan selama 10 bulan dari periode bulan Februari-November 2016. IbM dirancang dalam bentuk pelatihan dan praktek. Pertama, pelatihan terhadap kelompok nelayan dan wanita nelayan tentang (i) Jaminan mutu dan keamanan hasil perikanan pada proses produksi, pengolahan dan distribusi peningkatan daya tahan hasil tangkapan perikanan sehingga mampu meningkatkan proses produksi, mutu, dan daya tahan; (ii) Pelatihan jenis, fungsi, karakteristik kemasan produk pangan sehingga mampu meningkatkan daya tahan dan kemasan. Kedua, praktek proses produksi bubuk terasi kering dengan pengeringan oven $150^{\circ} \mathrm{C}$ selama 30 menit dan inovasi kemasan menggunakan plastik poliproplin 0,6 mm dan kemasan sekunder.

Rencana kegiatan program loM sebagai berikut: (1) Persiapan pelaksanaan yang mencakup survei lapangan, pengurusan adminsirasi, penyebaran undangan kepada mitra untuk mengikuti pelatihan dan praktek pengawetan hasil tangkapan perikanan, mutu, dan pengemasan produk bubuk terasi udang rebon kering; (2) Pelaksanaan kegiatan yang mencakup pelatihan dan praktek 
pengawetan hasil tangkap, proses produksi, dan pengemasan bubuk terasi udang rebon; (3) Monitoring dan evaluasi. Monitoring akan dilakukan selama kegiatan untuk elihat hambatan yang dihadapi serta kemajuan program yang telah dilaksanakan. Evaluasi dilaksanakan setelah program berakhir untuk mengukur kesesuaian antara target luaran yang direncanakan dengan kondisi empirisnya; (4) Usaha keberlanjutan program secara efektif untuk meningkatkan perannya bagi masyarakat sekitar.

Tahapan partisipasi mitra dalam pelaksanaan lbM: (1) Survei dan observasi lapangan berdasarkan potensi yang ada sesuai kebutuhan masyarakat; (2) Penentuan teknis pelaksanaan program kegiatan dan kelompok yang dilibatkan dalam pelatihan dan prakteknya; (3) Perencanaan keberlanjutan program pelatihan.

\section{HASIL DAN PEMBAHASAN}

Hasil yang dicapai dari l bM sebagai berikut: (1) Produk bubuk terasi kering yang sebelumnya hanya berupa terasi padat berbentuk kotak atau bulat; (2) Kemasan produk dari plastik poliproplien yang aman sebagai kemasan pangan yang sebelumnya hanya dikemas dengan daun atau bungkus koran/kertas sehingga lebih tahan lama dan hiegenis; (3) Produk memiliki label dengan desain yang lebih menarik; (4) Nama produk yang menjadi identitas khas produk kelompok wanita nelayan; (5) Pengetahuan bagi kelompok wanita nelayan karena mengikuti pelatihan oleh Dinas Kesehatan Kab. Sambas; (6) Produk bubuk terasi kering memiliki PIRT; (7) Bantuan alat pengawetan dan pengolahan hasil tangkapan udang rebon untuk kelompok nelayan berupa cool storage, serta untuk kelompok wanita nelayan seperti impulse sealer powerpack, vacum sealer, timbangan digital, oven pengering, hand plastic sealer, pengayak, pematik api, stempel, label kemasan, talenan, apron dan lain-lain.

Untuk menjaga keberlanjutan usaha pembuatan terasi bubuk kering oleh industri rumah tangga yang dikelola Kelompok wanita nelayan tersebut maka ada beberapa kegiatan tahapan berikutnya yang dapat dilakukan oleh stakeholders. Pertama, bersama pemerintah daerah setempat (Dinas Kesehatan, Dinas Perindustrian dan Perdagangan, dan dinas-dinas yang terkait) melakukan kunjungan rutin untuk membina kelompok tersebut terkait informasi dan pelatihan serta kebijakan pendukung industri rumah tangga untuk pemberdayaan masyarakat sekitar. Pelatihan tersebut terkait: (i) Cara produksi yang memperhatikan aspek keamanan pangan bagi IRTP untuk memproduksi pangan yang bermutu, aman dan layak dikonsumsi dengan tujuan memberikan 


\section{Website : http:// jurnal.untan.ac.id/ index.php/JPLP2KM ISSN : 2620 - 4665 (print) ISSN : 2620 - 4673 (online)}

prinsip-prinsip dasar keamanan pangan bagi IRTP dalam menerapkan CPPB-IRT agar dapat menghasilkan produk pangan yang aman dan bermutu sesuai dengan tuntutan konsumen baik konsumen domestik maupun internasional; (ii) Persyaratan-persyaratan yang harus dipenuhi tentang penanganan pangan di seluruh mata rantai produksi mulai dari bahan baku sampai produk akhir; (ii) Pelatihan dan pemberian informasi tentang lingkungan produksi, bangunan dan fasilitas IRT, peralatan produksi, suplai air, fasilitas dan kegiatan higenis serta sanitsi, kesehatan dan higenitas karyawan, pemeriharaan dan program higenitas dan sanitai, penyimpanan, pengendalian proses, label pangan, pengawasan oleh penanggungjawab, penarikan produk, dan pelatihan karyawan.

Kedua, memberikan pelatihan dan demonstrasi peningkatan kualitas produk terasi kering bubuk dengan teknologi yang lebih baik sehingga rasa dan keamanan produk menjadi lebih baik dengan penambahan angkak sebagai pewarna alami dan sumber antioksidan (lihat Gambar 1). Terasi merupakan bumbu tradisional yang banyak dikenal dan disukai karena rasa dan aromanya yang khas, terutama untuk meningkatkan selera makan. Produk ini berbentuk seperti pasta dan blok dan berwarna hitam-coklat. Akan tetapi terasi yang disukai oleh konsumen adalah terasi yang berwarna merah yang terlihat menarik. Hal ini mendorong produsen menggunakan pewarna buatan dalam proses pembuatannya. Pewarna buatan yang terkadang digunakan yaitu Rhodamin B. Padahal Rhodamin B merupakan pewarna untuk kertas dan tekstil sehingga pewarna ini berbahaya bagi kesehatan seperti iritasi bila terkena mata, menyebabkan kulit iritasi dan kemerahan, dan penyebabkan kanker.

Permasalahan ini mendorong untuk penggunaan pewarna alami pada pembuatan terasi. Salah satu pewarna alami yang berpigmen merah yaitu angkak. Angkak adalah bahan pewarna alami yang dihasilkan oleh kapang Monascus pupureus, memiliki warna yang konsisten dan stabil, dapat bercampur dengan pigmen alami lainnya dan dengan bahan makanan, tidak mengandung racun dan tidak karsinogen sehingga dapat digunakan sebagai pewarna alami untuk makanan. Komponen pigmen yang dihasilkan oleh angkak adalah rubropunktatin (merah), monaskorubin (merah), monaskin (kuning), ankaflavin (kuning), rubropunktamin (ungu), dan monaskorubramin (ungu) dan lebih dominan warna merah. Pada angkak menghasilkan antioksidan monacolin $\mathrm{K}$ disebut juga lovastatin atau mevalonin) yang dapat menurunkan kadar lipid dengan cara menghambat aktivitas HMG-CoA reductase dalam intesis kolesterol pada hati (Fardiaz dkk, 1996). 
Website : http:// jurnal.untan.ac.id/ index.php/JPLP2KM ISSN : 2620 - 4665 (print)

ISSN : 2620 - 4673 (online)

Kandungan pewarna alami dan senyawa antioksidan dalam angkak diharapkan menjadi pewarna alami dan sumber antioksidan pada terasi.

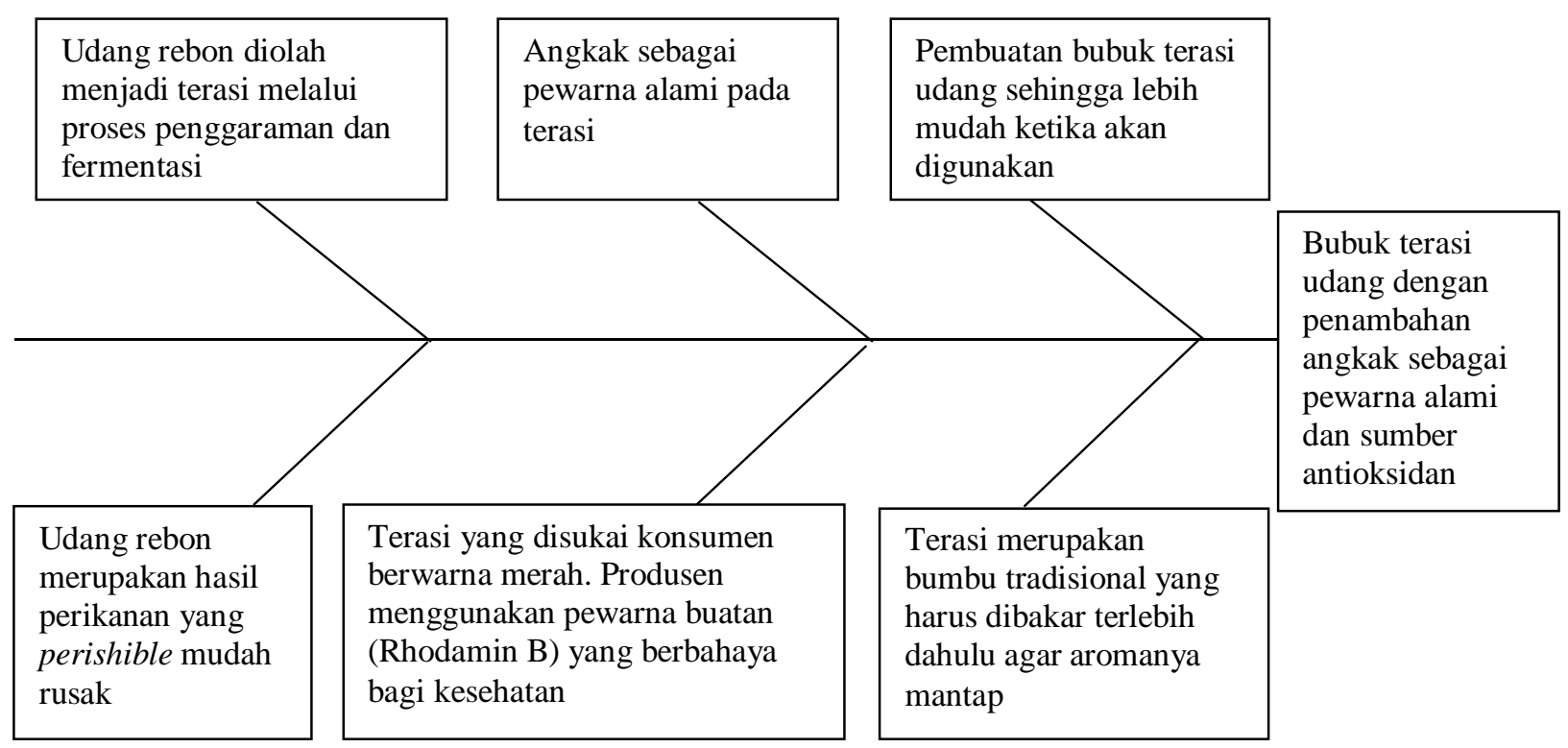

Gambar 1. Penambahan Angkak sebagai Pewarna Alami dan Sumber Antioksidan 


\section{Website : http:// jurnal.untan.ac.id/ index.php/JPLP2KM ISSN : 2620 - 4665 (print) \\ ISSN : 2620 - 4673 (online)}

Ketiga, memberikan pelatihan tentang pengembangan produk agar dapat bertahan dan bersaing dengan produk lainnya serta menghadapi perubahan-perubahan dinamis, seperti perubahan ekonomi, perubahan sosiologi dan demografi, perubahan teknologi, perubahan konflik, serta perubahan lainnya seperti dinamika pasar, standarisasi, pemasok, dan penyalur. Keempat, memberikan pelatihan terkait riset pasar yang nantinya dapat menjadi dasar perumusan strategi pemasaran dan distribusi terhadap produk terasi bubuk kering udang rebon tersebut di pasar-pasar lokal maupun kabupaten/kota lainnya.

\section{SIMPULAN DAN REKOMENDASI}

Pemberdayaan kelompok nelayan dan wanita nelayan dapat berkembang jika difasilitasi dan didukung eksistensinya oleh masyarakat dan pemerintah daerah setempat sehingga sosialisasi dan pelatihan jaminan keamanan pangan sebagai informasi bagi berkembangnya industri rumah tangga sangat diperlukan bagi pemberdayaan masyarakat nelayan sekitar. Keberadaan produk olahan terasi yang aman dan higienis dapat dijadikan perintis untuk pengembangan produk dan pemasaran lebih lanjut sehingga mampu meningkatkan pendapatan masyarakat nelayan sekitar. Oleh sebab itu, pemerintah daerah dapat terus melakukan pemantauan dan pembinaan usaha tersebut sehingga dapat berkembang dan dinikmati hasilnya serta melakukan inovasi produk dan kemasan agar menarik dan kompetitif secara berkelanjutan.

\section{DAFTAR PUSTAKA}

Anisah, Rifka Nur. 2007. Analisis Tingkat Keberdayaan Pengolah Ikan Yang Berorientasi Pasar. Thesis Program Pascasarjana Universitas Diponogoro Semarang. (tidak dipublikasikan)

Direktorat Jenderal Perikanan Tangkap. 2001. Inventarisasi Jenis dan Jumlah Produk Olahan Hasil Perikanan Skala Kecil di Indonesia.Departemen Kelautan dan Perikanan, Jakarta.

Huseini, Martani. 2007. Masalah dan Kebijakan Peningkatan Produk Perikanan untuk memenuhi Gizi Masyarakat. Seminar Nasional Hari Pangan Sedunia XXVII. Dukung dan Teknologi Untuk Meningkatkan Produk Pangan Hewani Dalam Rangka Pemenuhan Gizi Masyarakat. Direktur Jenderal Pengolahan dan Pemasaran Hasil Perikanan Departemen Kelautan dan

Perikanan. http://www.litbang.pertanian.go.id/special/HPS/kebijakan_perikanan.pdf

Ibrahim, Ratna. 2003. Mutu Hasil Perikanan dan Peranannya dalam Menghadapi Pasar Global. Makalah Pelatihan Pengetahuan Mutu. UNDIP. Semarang

Maflahah, Iffan. 2013. Kajian Potensi Usaha Pembuatan Terasi Udang Studi Kasus Desa Bantelan, Kecamatan Batu Putih, Kabupaten Sumenep. Agrointek Volume 7, No. 2 Agustus 2013. 
Website : http://jurnal.untan.ac.id/ index.php/JPLP2KM ISSN : 2620 - 4665 (print)

ISSN : 2620 - 4673 (online)

Mega Mulya, Junaidi, dan Ermi Husni. 2013. Analisis Faktor-Faktor yang Mempengaruhi Pemasaran Produk Olahan ikan Laut Di Kota Padang. Vol 3, No 2, Tahun 2013. http://ejurnal.bunghatta.ac.id/index.php?journal=FPIK\&page=article\&op=view\&path\%5B $\% 5 \mathrm{D}=1878$

Riyadi, Putut Har. 2006. Analisis Kebijakan Keamanan Pangan Produk Hasil Perikanan Di Pantura Jawa Tengah dan DIY. Thesis Program Pascsarjana universitas Diponogoro Semarang. (tidak dipublikasikan)

Yusuf, Muhammad. 2007. Kajian Pemasaran dan Pengembangan Value Added Product dengan Pemanfaatan Ranjungan Menjadi Produk Olahan. Thesis Program Pascsarjana universitas Diponogoro Semarang. (tidak dipublikasikan) 